\title{
G/T Mismatch-Specific Thymine DNA Glycosylase
}

National Cancer Institute

\section{Source}

National Cancer Institute. G/T Mismatch-Specific Thymine DNA Glycosylase. NCI

Thesaurus. Code C101585.

$\mathrm{G} / \mathrm{T}$ mismatch-specific thymine DNA glycosylase (410 aa, $\sim 46 \mathrm{kDa}$ ) is encoded by the human TDG gene. This protein is involved in DNA repair. 